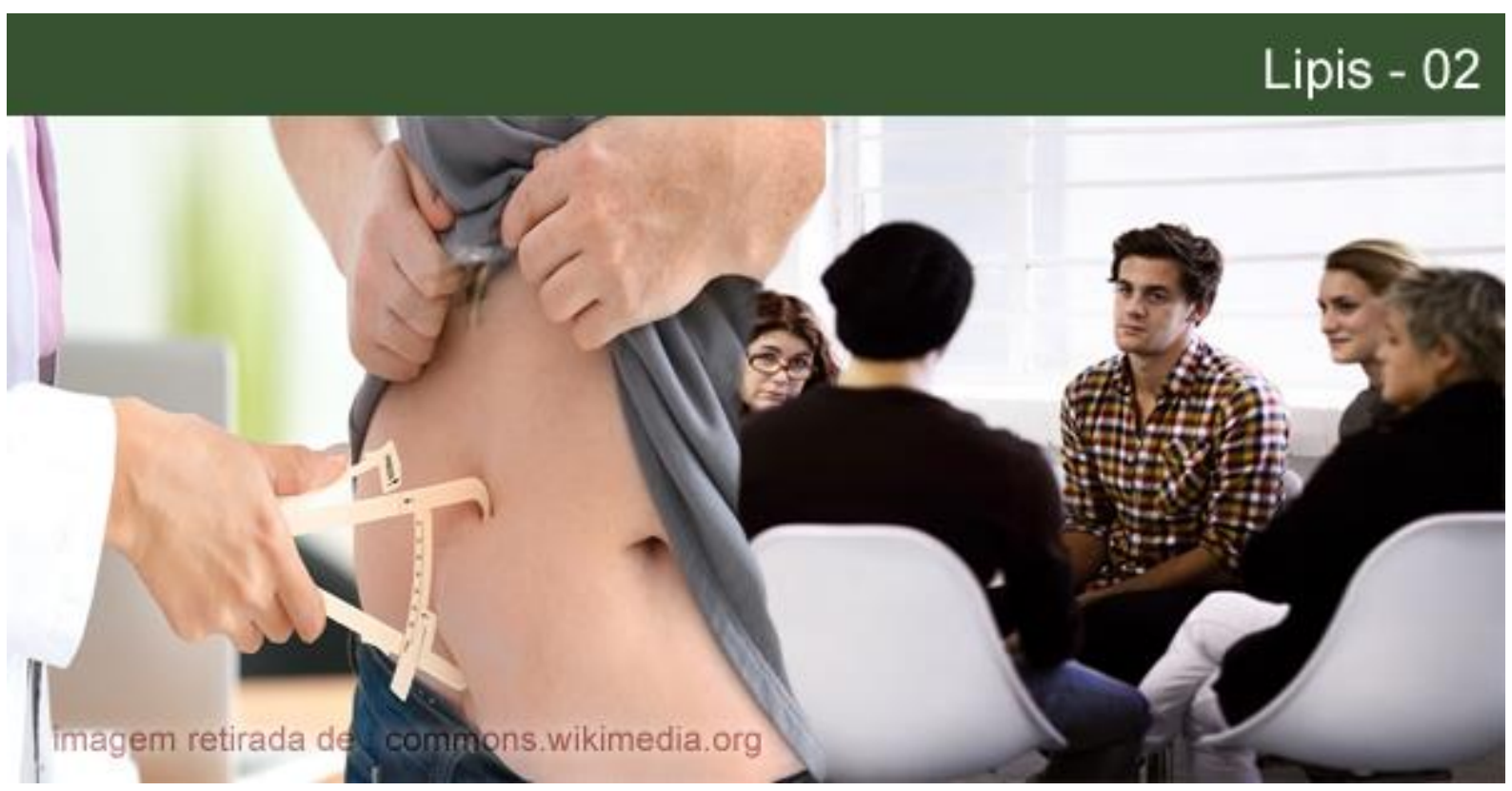

\title{
A EXPERIÊNCIA DE INTERVENÇÃO GRUPAL COMO AMBIENTE FACILITADOR EM UM AMBULATÓRIO DE CIRURGIA BARIÁTRICA
}

\begin{abstract}
Nelia Mendes
Doutoranda em Psicologia Clínica pela Pontifícia Universidade Católica (PUC-Rio). Pesquisadora e psicoterapeuta do Laboratório Interdisciplinar de Pesquisa e Intervenção Social (LIPIS/PUC-Rio). Psicóloga do Serviço de Psicologia Médica - Hospital Federal Servidores do Estado (HFSE/RJ).

E-mail: neliamendes@gmail.com.

\section{Joana Novaes}

Professora do Programa de Mestrado Profissional e Doutorado em Psicanálise, Saúde e Sociedade da Universidade Veiga de Almeida. Pós-Doutorado em Psicologia Social e em Psicologia Médica pela Universidade do Estado do Rio de Janeiro (UERJ) e Doutorado em Psicologia (Psicologia Clínica) pela Pontifícia Universidade Católica (PUC-Rio). Especialista em Transtornos Alimentares pela Santa Casa de Misericórdia do Rio de Janeiro. Coordenadora do Núcleo de Doenças da Beleza do Laboratório Interdisciplinar de Pesquisa e Intervenção Social (LIPIS/PUC-Rio). Pesquisadora correspondente do Centre de Recherches Psychanalyse et Médecine -Université Denis-Diderot Paris 7, CRPM-Pandora.E-mail: joanavnovaes@gmail.com.
\end{abstract}

\section{Junia de Vilhena}

Psicanalista. Professora do Departamento de Psicologia da Pontifícia Universidade Católica (PUC-Rio). Doutora em Psicologia. Coordenadora do Laboratório Interdisciplinar de Pesquisa e Intervenção Social (LIPIS/PUC-Rio). Investigadora-Colaboradora do Instituto de Psicologia Cognitiva da Universidade de Coimbra. Pesquisadora correspondente do Centre de Recherches Psychanalyse et Médecine, CRPM-Pandora, Université Denis-Diderot Paris VII. E-mail: juniavilhena@gmail.com.

Resumo: Em uma realidade hospitalar, onde é cada vez mais expressivo o número de encaminhamentos ao SUS de pessoas obesas candidatas à cirurgia bariátrica, ganha destaque a inevitabilidade de se produzir dispositivos ou modalidades de tratamento, como os grupais, que garantam acesso ao acompanhamento psicológico de todos os candidatos ao procedimento. O objetivo é apresentar o grupo operativo como recurso de atendimento psicológico utilizado em um ambulatório público de cirurgia bariátrica em um hospital da rede federal na cidade do Rio de Janeiro. Trata-se de um estudo teórico realizado pelo viés psicanalítico. O artigo aponta que a escolha por contemplar atendimentos em grupo coaduna-se mais com a valorização desse dispositivo como prática onde a

\section{POLÊM!CA $\mid$ LABORE}

Polêmica - Revista Eletrônica da Uerj - Rua São Francisco Xavier, 524, $1^{\circ}$ andar bloco D, sl.1001 • Tels.: +55 21 2334-4088 / 4087 • http://www.e-publicacoes.uerj.br/index.php/polemica/index http://www.labore.uerj.br • laboreuerj@yahoo.com.br 
escuta mútua possibilita caminhos e resoluções significativas para as pessoas, do que por ser uma estratégia de manejo em massa. Resultando em uma experiência exitosa para a promoção de saúde mental, preparo cirúrgico e suporte emocional oferecidos a essa população específica.

Palavras-chave: Obesidade. Cirurgia bariátrica. Grupo operativo. Pichon-Riviére.

\title{
THE GROUP INTERVENTION EXPERIMENT AS A FACILITATING ENVIRONMENT IN AN BARIATRIC SURGERY CLINIC
}

\begin{abstract}
In a hospital reality in which the number of referrals to the SUS (Brazilian public health system) of obese people entitled to bariatric surgery is increasingly meaningful, the unavoidable production of devices or types for treatment becomes of great importance, such as groups which can ensure access to psychological treatment to all candidates. The aim is to present the operating group as a psychological care resource used in a public outpatient clinic of bariatric surgery in a hospital of the federal network in the city of Rio de Janeiro. It is a theoretical study carried out by the psychoanalytic bias. However, the choice to contemplate group attendance is more in keeping with the valorization of this device as a practice where mutual listening enables significant paths and resolutions for people, rather than being a strategy of mass management. Resulting in a successful experience for the promotion of mental health, surgical preparation and emotional support offered to this specific population Keywords: Obesity. Bariatric surgery. Operative group. Pichon-Rivière.
\end{abstract}

\section{Introdução}

Desempenho é o nome da mais nova forma de dominação e o campo da publicidade o novo promotor da chamada ascese corporal - uma espécie de calvinismo ${ }^{1}$ revisitado, do culto ao corpo, na sociedade de consumo. O corpo, enquanto capital, encarna todo o poder e prestígio que dele emanam, posto ser o lócus primordial de investimento libidinal do sujeito contemporâneo, quer seja através das práticas corporais de inclusão social, quer seja através das inúmeras patologias psicossomáticas que abundam, observadas através das demandas que chegam aos consultórios particulares e clínicas sociais. Consumir ou sumir, eis a questão. Somos a sociedade das academias fitness, andamos sem sair do lugar, hipnotizados diante de esteiras que nos prometem o corpo perfeito, em ambientes de sociabilidade suada e monitorada! Vivemos em estado constante de fadiga - é a Sociedade do Controle e do Cansaço (HAN, 2015) -, que nos afirma sem cessar que o poder na sociedade do desempenho é o verbo modal passivo presente na emblemática máxima: “Yes we can!’. Do mesmo modo, substituímos a lei pela iniciativa e pela motivação. Dentro dessa perspectiva, a vida converte-se em um projeto e o corpo assume um lugar protagônico.

Se é legítimo afirmar que a Sociedade Disciplinar produzia loucos e delinquentes, a Sociedade do Cansaço produz, como apontou Ehrenberg (2010), deprimidos e fracassados. O

\footnotetext{
${ }^{1}$ Conjunto de ideias e doutrinas com raízes na Reforma Protestante, que tem em João Calvino seu principal expoente. Segundo o calvinismo, a garantia de que alguém havia sido predestinado por Deus à salvação estava em seu sucesso pessoal, ou seja, uma pessoa próspera e bem-sucedida (profissão, saúde, família, etc.) demonstrava o favor de Deus para com ela.
}

\section{POLÊM!CA $\mid$ LABORE}

Polêmica - Revista Eletrônica da Uerj - Rua São Francisco Xavier, 524, $1^{\circ}$ andar bloco D, sl.1001 • Tels.: +55 21 2334-4088 / 4087 • http://www.e-publicacoes.uerj.br/index.php/polemica/index http://www.labore.uerj.br • laboreuerj@yahoo.com.br 
discurso dominante atual parece exigir que encontremos a maneira adequada de produzir capital, desejo e pensamentos positivos, caso contrário, amargaremos o peso da exclusão socialmente validada. O cansaço, por sua vez, aparece como uma nova forma de ser e existir, exausto, o sujeito contemporâneo vive o conflito de estar sempre aquém do que deveria. Maximizar a produção é o axioma que ancora a mentalidade atual, como um sintoma social. Assim, uma vez cansados, nos mantemos disciplinados, docilizados...

Nesse sentido, o imperativo do desempenho nos levaria ao cansaço. No entanto, sabemos não ser possível alcançar um estado de bem-estar subjetivo, vivendo sob pressão. Tampouco, é possível produzir para si sem, no entanto, produzir a si mesmo. Como bem nos lembra Foucault (2006), cuidar de si pressupõe negar, dizer não ao discurso normativo e às forças que trabalham no sentido de reproduzir o poder, do contrário, sujeitos acanhados, vivenciamos a existência mais próxima do mínimo possível.

Liberdade e coação, uma fórmula tão cômica quanto paradoxal: ajo segundo a minha própria vontade produzida pelos outros, - donde livre coerção equivale à autoexploração. Um Eu mínimo, como apontara Lasch (1986), nos idos anos oitenta, um Eu de superfície, identificado por Sibilia (2008), intitulado de Éxtimo. Uma fórmula eficaz que o nosso capitalismo tardio foi capaz de inventar, na qual mais eficaz do que a exploração do outro é a exploração de si mesmo.

Dentro desse contexto, a invenção de si mesmo, através do aperfeiçoamento corporal, apresenta-se como uma das formas de bem-viver. Cuidar de si, através de um extenuante protocolo corporal, configura, pois, uma ética contemporânea, sendo, portanto, legítimo afirmar que os cuidados com a aparência, de um direito passam então a configurar um dever, - e a não adesão às normas vigentes, uma transgressão. É neste cenário cultural que a criminalização da gordura, enquanto uma derivação do fenômeno social de moralização da beleza, causa tanto sofrimento psíquico, levando um número cada vez maior de sujeitos a lançar mão de técnicas radicais como forma de alívio e supressão do estigma social.

Em um mundo globalizado retratado graficamente, a linha que representa o número de pessoas obesas que atualmente necessitam de uma cirurgia bariátrica apresenta uma surpreendente curva ascendente. Surpreendente, pois o desenvolvimento da obesidade no mundo se deu de forma célere impactando severamente a saúde dos indivíduos e reivindicando meios para que essa disparada ganhasse contornos menos prejudiciais. Surpreendente também,

\section{POLÊM!CA $\mid$ LABORE}

Polêmica - Revista Eletrônica da Uerj - Rua São Francisco Xavier, $524,1^{\circ}$ andar bloco D, sl.1001 • Tels.: +55 21 2334-4088 / 4087 • http://www.e-publicacoes.uerj.br/index.php/polemica/index http://www.labore.uerj.br • laboreuerj@yahoo.com.br 
porque nunca se observou, em uma perspectiva histórica, o corpo tão evidenciado e mimetizado a ideais de felicidade, saúde e bem-estar, como é admitido o corpo magro, na atualidade.

Os dados da Sociedade Brasileira de Cirurgia Bariátrica e Metabólica (SBCBM, 2017) ratificam o aumento do número de cirurgias bariátricas no Brasil, considerado, atualmente, o segundo país no mundo em número de procedimentos realizados, atrás apenas dos Estados Unidos. Em 2017, por exemplo, foram realizados 105.642 procedimentos.

Equivocam-se, entretanto, os que pensam que a cirurgia age apenas pela restrição na ingestão alimentar causada mecanicamente com a diminuição do estômago. Na verdade, ela causa efeitos metabólicos e alterações profundas na fisiologia daqueles que a ela se submetem, transformando os mecanismos neurais e hormonais e impactando o complexo sistema de sinalização hormonal do sistema digestivo para o cérebro.

Isto posto, fica evidente que a cirurgia bariátrica exige do candidato ao procedimento modificações que vão para além das alimentares. Da mesma maneira, o cuidado disponibilizado pela equipe deve ser multidisciplinar, organizado a partir de modelos que abordam os aspectos biopsicossociais que se interrelacionam para produzir o quadro de obesidade. O tratamento para ser efetivo necessita ser integral e também centrado na pessoa e não organizado somente ao redor da doença, pois a modificação do indivíduo e de sua forma de viver são mister para o alcance da resposta desejada.

Nesta visada, Mendes e Vilhena (2016) reconhecem que as transformações de estilo de vida, comportamentais e psicológicas adquirem realce porque prescindir da obesidade e sustentar uma escolha pela cirurgia bariátrica implicam em uma reflexão sobre o porquê e para que o psiquismo organizou-se em torno de um corpo pesado. A simbolização desse corpo fazse necessária, assim como a reflexão de como o sujeito específico que busca a cirurgia bariátrica tem se servido desse corpo de excessos até então. Tarefa clínica ímpar e de grande monta que possui coadjuvância para o êxito do procedimento.

Assim, nesse artigo, apresentamos o grupo operativo como dispositivo de atendimento psicológico, promoção de saúde mental, preparo e suporte oferecido aos pacientes de cirurgia bariátrica de um ambulatório público, na cidade do Rio de Janeiro. Ele, ao auxiliar na minimização dos medos básicos e no favorecimento do rompimento de estereótipos que funcionam como barreira às mudanças, apresenta-se como recurso significativo para essa comunidade.

\section{POLÊM!CA $\mid$ LABORE}

Polêmica - Revista Eletrônica da Uerj - Rua São Francisco Xavier, 524, $1^{\circ}$ andar bloco D, sl.1001 • Tels.: +55 21 2334-4088 / 4087 • http://www.e-publicacoes.uerj.br/index.php/polemica/index http://www.labore.uerj.br • laboreuerj@yahoo.com.br 
Seu caráter terapêutico também é considerado, pois a identificação entre seus membros, esclarecimento quanto às fantasias relacionadas ao procedimento e pós-operatórios, assim como o acolhimento de ansiedades e angústias relacionadas a todo processo são tomados como referências para o trabalho clínico e elegibilidade do recurso grupal lado a lado ao recurso de atendimento individual como protocolo psicológico para a avaliação, preparo e acompanhamento dos pacientes assistidos pela equipe de cirurgia bariátrica desse hospital.

\title{
Grupo e sua função de sustentação
}

\begin{abstract}
À medida que o bebê aprende a engatinhar, e mais tarde a andar, a função de sustentação da mãe é gradualmente substituída pelo solo..., nesta ideia da função materna de proporcionar um sentimento de segurança... existe, aqui, um relacionamento vitalmente importante entre o bebê e a sua mãe [...] Estamos nos aproximando da tão conhecida observação de que a ansiedade mais antiga é aquela relativa a sentir-se segurado de um modo inseguro... Certos tipos de ansiedade no início da infância podem ser evitados pelo cuidado suficientemente bom (WINNICOTT, 1952, p. 163).
\end{abstract}

A experiência de Winnicott na área de pediatria lhe permitiu estabelecer uma teoria voltada para as fases mais precoces do desenvolvimento emocional da criança, ao reconhecer os vínculos emocionais nas etapas iniciais da organização psíquica e a dependência que ali se estabelecia com os objetos primários, considerando as falhas ambientais como fator etiológico dos transtornos psicológicos. Para o psicanalista, cada ser humano traz ao nascer um potencial inato para amadurecer, para se integrar. Embora inata, a tendência não garante sua consecução que dependerá de um ambiente facilitador que forneça cuidados suficientemente bons. Ambiente que inicialmente é representado pela mãe, ou substituta desta.

Cabe ressaltar que esses cuidados são individualizados e dependem da necessidade de cada criança, pois cada ser humano responderá ao ambiente de forma própria, apresentando condições, potencialidades e dificuldades diferentes. Assim, pode-se entender que não se trata apenas de um bem-sucedido cumprimento de tarefas mecânicas como dar de comer, fazer a higiene ou pôr para dormir. É importante que a mãe ambiente, suficientemente boa, perceba como satisfazer seu bebê, reconhecendo-o em suas especificidades.

Uma mãe que não "narcisou" suficientemente seu bebê (por exemplo, fazendo-o crer que havia algo de errado com ele) não sustentou o ego ideal pelo tempo necessário. Assim, a busca de ser o próprio ideal - a busca pela perfeição narcísica, condição para ser amado pelas figuras parentais - continua pela vida afora. (MINERBO, 2009, p. 146).

\section{POLÊM!CA | LABORE}

Polêmica - Revista Eletrônica da Uerj - Rua São Francisco Xavier, 524, $1^{\circ}$ andar bloco D, sl.1001 • Tels.: +55 21 2334-4088 / 4087 • http://www.e-publicacoes.uerj.br/index.php/polemica/index http://www.labore.uerj.br • laboreuerj@yahoo.com.br 
Minerbo (2009) destaca neste trecho a importância da relação mãe-bebê, para a inscrição deste narcisismo primário e, consequentemente, do ego ideal, já que é neste momento que se inscreve no bebê uma imagem jubilosa de si. Ao abordarem a questão do olhar materno na subjetivação do bebê, Pinheiro, Quintella e Verztman (2010) ressaltam que quando o olhar materno não circunscreve este indivíduo, não o insere na dinâmica da pluralidade identificatória, resta ao bebê apenas uma profunda identificação com o nada, que o lança em um vazio sem precedentes.

Tal vazio é queixa constante na clínica de pacientes obesos que tentam, por intermédio da comida, não somente tamponar o vazio corporal, mas afastar-se da angústia do vazio, normalmente expressa em sensações corporais não descritíveis ou representáveis, que os levam compulsivamente a comer, subjugados a um excesso que não se satisfaz, a uma falta que não é preenchida e que nos remete à falência deste eu ideal, uma ferida narcísica decorrente da impossibilidade de luto diante da perda ou da não-inscrição de sua onipotência infantil, uma defesa excessiva diante da angústia de separação do objeto.

Ramalho (2001) também destaca o papel do olhar materno, portador do desejo do outro materno, como constitutivo do sujeito. Segundo a autora:

Nas neuroses narcísicas o ideal permanece sempre inacessível ao sujeito, que fica
confinado à sensação de insuficiência, fazendo-o vacilar em sua identidade. Esta
fragilidade narcísica surge por sentirem não haver encontrado um lugar para si no
desejo materno, um reconhecimento enquanto sujeito, persistindo em seu sofrimento
um apelo identitário para aceder a uma condição subjetiva (RAMALHO, 2001, p. 51).

Retomemos, contudo, Winnicott (1983) e sua memorável relevância no estudo e no manejo do mecanismo da regressão. $\mathrm{O}$ acento ao tema em sua obra traz consequências diretas ao manejo da técnica, sendo fundamental o reconhecimento de que cada paciente possui seu próprio ritmo e, tal qual a mãe suficientemente boa, deve ter condições de reconhecer as particularidades de seu bebê, o analista deve respeitar os diferentes tempos no curso do desenvolvimento de seus pacientes.

A compreensão da questão da regressão em psicanálise, sobretudo, no ambiente hospitalar, nos é particularmente cara. Concebida como um mecanismo de defesa, seu exame aponta mais para a existência de uma organização egóica e uma ameaça de caos - angústias impensáveis - do que para o uso popular que se faz do termo. Essas poderiam ser lidas como a quebra da continuidade do sentimento de ser e após tais vivências, são organizadas defesas a

\section{POLÊM!CA | LABORE}

Polêmica - Revista Eletrônica da Uerj - Rua São Francisco Xavier, 524, $1^{\circ}$ andar bloco D, sl.1001 • Tels.: +55 21 2334-4088 / 4087 • http://www.e-publicacoes.uerj.br/index.php/polemica/index http://www.labore.uerj.br • laboreuerj@yahoo.com.br 
fim de evitar essas angústias. Assim, quando expostos a um ambiente traumático, há a interrupção dos processos de maturação egóica, favorecendo o colapso dos processos integrativos.

A atualização de um modo de funcionamento psíquico ligado a etapas mais precoces do desenvolvimento permite a satisfação de necessidades afetivas primitivas. Todavia, essa atualização pressupõe que para regredir a um estágio anterior "é necessário que alguém consiga perceber essa necessidade e possa colocar-se em condições de preenchê-la" (KHAN, 2000). Winnicott (1954) sublinha que o bom entendimento da técnica conduz o analista a cooperar com o seu paciente no seguimento de um processo que é singular, pois cada paciente possui seu próprio ritmo e caminha no seu próprio rumo.

A mãe suficientemente boa é aquela capaz de satisfazer as necessidades do bebê no início, e satisfazê-las tão bem que a criança, na sua saída da matriz do relacionamento mãefilho, é capaz de ter uma breve experiência de onipotência. Sua ausência, ou de alguém que se disponibilize para exercer tal função, abala a maturação do ego ou faz com que o desenvolvimento do ego ocorra necessariamente distorcido em certos aspectos vitalmente importantes. Nesse estágio, o bebê é um ser imaturo que está “continuamente a ponto de sofrer uma ansiedade inimaginável" (WINNICOTT, 1962, p. 56), que pode ser evitada pela mãe e sua capacidade de se pôr no lugar do bebê e saber o que ele necessita no cuidado geral do seu corpo e, por consequência, de sua pessoa como suporte para o vir a ser.

A potência promotora de saúde mental dos dispositivos grupais é destacada pelo inevitável paralelo com a teorização winnicottiana a respeito da importância do ambiente nos processos de maturação emocional do bebê. Assim, a importância de um ambiente facilitador para o desenvolvimento da natureza humana embasa a obra de Winnicott e anima a manutenção do dispositivo grupal para os pacientes do programa de cirurgia bariátrica.

Compreendido desta maneira, o grupo em sua função de sustentação ou como holding é a tradução do acolhimento necessário aos seus membros e ao funcionamento amoroso e empático que dele se espera. O holding é sustentação que permitirá que cada um dos membros do grupo possa desenvolver seu potencial em direção à autonomia, internalizando os cuidados recebidos como forma de acreditar em seus próprios recursos de enfrentamento para lidar com as situações adversas que possam surgir em seu contato com o novo e com o mundo.

\section{POLÊM!CA | LABORẸ}

Polêmica - Revista Eletrônica da Uerj - Rua São Francisco Xavier, $524,1^{\circ}$ andar bloco D, sl.1001 • Tels.: +55 21 2334-4088 / 4087 • http://www.e-publicacoes.uerj.br/index.php/polemica/index http://www.labore.uerj.br • laboreuerj@yahoo.com.br 
Em paralelo à obra winnicottiana, a não sustentação do grupo pode ocasionar o sentimento de desintegração, gerando angústia de aniquilamento. O apoio do grupo é, segundo relatos dos pacientes, fundamental. A presença empática do grupo é uma aproximação da sintonia mãe-bebê, e da capacidade da primeira dessa díade de captar e entender as mensagens do seu bebê, provendo-o do que ele necessita. Deste modo, o grupo funciona como o ambiente que auxilia na provisão para a concretização no rumo à independência de seus participantes, pois o olhar do grupo é significativo para cada um dos membros que dele fazem parte. Através dele, o sujeito pode se ver, se pensar e se implicar em seu projeto.

A aproximação da abordagem winnicottiana com a função do grupo terapêutico vem sendo explorada por vários autores. Podemos citar, entre tantos, Campos (2007) e Corbisier (2011). Essa última, propõe a analogia entre grupo e a relação mãe-bebê. Nessa aproximação, o grupo é apresentado a partir da metáfora "uma barriga cheia de bebês", ou seja, a barriga/grupo como um espaço transicional entre o fora (mundo) e o dentro (a subjetividade de cada participante).

Para Corbisier (2011), cada sessão de grupo pode ser compreendida tal qual um parto, no qual conceitos tão presentes na obra de Donald Winnicott como de ambiente suficientemente bom, holding, handling e sentimento de confiança sustentando o desenvolvimento psíquico e físico de um bebê são utilizados como balizas para a elaboração dessa analogia. Nessa interessante perspectiva proposta pela autora, o grupo é o espaço transicional, que não está dentro nem fora, aquela posição intermediária entre o subjetivo e o objetivo. Ao estabelecer a conexão entre o grupo e a relação mãe-bebê, Corbisier demonstra a possibilidade de pensá-lo em termos de "ambiente suficientemente bom" e nos brinda com a sensível e cativante imagem do grupo como um ventre grávido sempre a parir novas criaturas.

Tal alegoria sugere a fusão inicial entre mãe/bebê que pouco a pouco, em um ambiente de confiança, vai se dissipando e abrindo lugar ao rumo à independência relativa. Entretanto, é importante ressaltar que a independência nunca é absoluta, uma vez que o indivíduo sadio não se torna isolado, mas se relaciona com o ambiente de tal modo que pode se dizer que ambos se tornam interdependentes. Pontua a autora que em um ambiente suficientemente bom, as “criaturas recém-paridas" podem interagir e criativamente, podem formular novas respostas na trajetória do fusional para a diferenciação.

\section{POLÊM!CA $\mid$ LABORE}

Polêmica - Revista Eletrônica da Uerj - Rua São Francisco Xavier, $524,1^{\circ}$ andar bloco D, sl.1001 • Tels.: +55 21 2334-4088 / 4087 • http://www.e-publicacoes.uerj.br/index.php/polemica/index http://www.labore.uerj.br • laboreuerj@yahoo.com.br 
Desta forma, o ambiente/grupo auxilia a tarefa de sensação de continuidade fundamental do vir a ser. O grupo-barriga, nesse delicado olhar de Corbisier, influenciado pelo pressuposto winnicottiano de que a saúde mental do indivíduo está intimamente ligada ao ambiente, possui relevância como o suporte que está na origem e é sustentáculo do necessário acolhimento para que seus membros se sintam suficientemente seguros.

\section{O grupo operativo e seus alcances}

Está posto que toda doença tem uma história natural médica plena de fatos em comum e de ocorrências que possibilitam que pessoas que dela sofram se identifiquem. Por isso, Melo Filho (2007), inspirado no arcabouço teórico winnicottiano, sustenta que toda doença tem um "campo intermediário de problemas próprios, um espaço transicional de fenômenos" que auxilia a constatação de que todos os pacientes submetidos à redução do estômago deverão atravessar e ultrapassar situações análogas: as etapas evolutivas da dieta (da líquida a branda), o aumento gradativo das porções, a retomada às atividades da vida diária, as relações socioafetivas que tendem a se transformar, o vínculo quase sempre conflituoso com a comida, o problema da grande sobra de pele que pode requerer novas intervenções cirúrgicas corretivas, as mudanças no esquema corporal e tudo o mais que esse dado de circunstâncias traz como consequências emocionais.

Portanto, mais próximos da ideia de que o atendimento em grupo é uma prática próspera por permitir a escuta mútua que possibilita a elaboração de resoluções diante problemas comumente vivenciados do que a simples escolha por uma estratégia mais prática e adequada para o atendimento em massa, elegeu-se o modelo de atendimento grupal em paralelo ao atendimento individual como dispositivos de cuidados psicológicos aos usuários deste programa de cirurgia bariátrica. A contribuição para a apropriação das inovações, reconstrução dos vínculos e elaboração das significações indispensáveis a modificações face às agudas e profundas transformações advindas da submissão ao procedimento bariátrico, está calcada sob a égide do grupo operativo, um ponto intermediário entre a psicanálise e o grupo comum, de apoio ou de suporte.

O grande nome nessa área é, sem dúvida, Enrique Pichon-Rivière, psicanalista argentino que desde 1945 desenvolveu e sistematizou a técnica. Partindo do conceito de Esquema Conceitual, Referencial e Operativo (ECRO), ele propôs um aprofundamento no estudo dos

\section{POLÊM!CA | LABORË}

Polêmica - Revista Eletrônica da Uerj - Rua São Francisco Xavier, $524,1^{\circ}$ andar bloco D, sl.1001 • Tels.: +55 21 2334-4088 / 4087 • http://www.e-publicacoes.uerj.br/index.php/polemica/index http://www.labore.uerj.br • laboreuerj@yahoo.com.br 
fenômenos surgidos no campo dos grupos que se instituem não por finalidade de terapia, mas com o propósito de operar uma determinada tarefa objetiva, como por exemplo, a de ensinoaprendizagem, dado que os grupos operativos se definem como grupos centrados na tarefa.

O ECRO foi elaborado considerando aspectos inconscientes e conscientes que regem a dinâmica dos grupos e que se revelam nas três áreas: mente, corpo e mundo exterior. Ele pode ser compreendido enquanto um modelo, que constituído como esquema conceitual e referencial, mostra seu caráter de instrumento para apreensão da realidade (PICHONRIVIÈRE, 2012).

Como modelo, ele proporciona a compreensão dos fatos a partir de uma organização ou articulação de conceitos universais, onde o aspecto referencial diz respeito ao campo, ou ainda, ao segmento de realidade sobre a qual se pensa e se opera. Já o critério de operatividade é elemento fundamental, pois representa a possibilidade de promoção de uma modificação criativa ou adaptativa segundo um critério de adaptação ativa à realidade, em relação com a conquista dos objetivos propostos.

As postulações de Pichon-Rivière são sustentáculo para uma diversidade de experiências em que são utilizadas aplicações da técnica dos grupos operativos. Nesse enquadramento, a psicoterapia não é o objetivo principal, mas algumas de suas consequências podem ser consideradas terapêuticas na medida em que instrumentaliza o sujeito para operar e agir na realidade. Assim, espera-se que grupo operativo como técnica auxilie a resolução das dificuldades internas de cada sujeito, tornando-o mais flexível e dialético, através da tarefa na qual se inclui o esclarecimento das resistências à mudança.

Zimerman (1997) ratifica a vasta aplicabilidade da técnica operativa: "e é tão extensa a gama de suas aplicações práticas, que muitos preferem considerá-los como sendo, genericamente, um continente de todos os demais grupos, inclusive os terapêuticos, mesmo os especificamente psicanalíticos" (ZIMERMAN, 1997, p. 76).

De forma panorâmica, os grupos operativos podem ser utilizados em quatro campos distintos: o do ensino-aprendizagem, o institucional, o comunitário e o terapêutico. Este último é muito utilizado no âmbito hospitalar para a melhora de alguma situação patológica - orgânica ou psíquica. Têm como característica serem grupos abertos e homogêneos, congregando pessoas que possuem aspectos semelhantes e que se reúnem para troca de experiências e ajuda

\section{POLÊM!CA $\mid$ LABORE}

Polêmica - Revista Eletrônica da Uerj - Rua São Francisco Xavier, $524,1^{\circ}$ andar bloco D, sl.1001 • Tels.: +55 21 2334-4088 / 4087 • http://www.e-publicacoes.uerj.br/index.php/polemica/index http://www.labore.uerj.br • laboreuerj@yahoo.com.br 
recíproca. Essa reunião pode se dar espontaneamente ou a partir do estímulo de algum profissional, que coordena o grupo.

Pichon-Rivière (2012) propõe o grupo operativo como um instrumento eficaz ao salientar que nele coincidem o esclarecimento, a comunicação, a aprendizagem e a resolução de situações de ansiedade. Segundo o autor, o grupo operativo assemelha-se ao funcionamento do grupo familiar e pode ser definido como um conjunto de pessoas reunidas por constantes de tempo e espaço, articuladas por sua mútua representação interna, que se propõe, implícita ou explicitamente, uma tarefa que constitui sua finalidade.

Um dos objetivos da técnica dos grupos operativos, como sinaliza Pichon-Rivière, é o de auxiliar na minimização dos medos básicos e o de favorecer o rompimento dos estereótipos que funcionam como barreira à mudança. Assim, uma comunicação significativa com os outros membros do grupo e a possibilidade de dar e receber feedbacks que auxiliem no exame dos aspectos ocultos dos próprios sentimentos e comportamentos são propostas da terapia de grupo.

Há também um forte caráter terapêutico no grupo ocasionado pela identificação de seus membros, suporte oferecido, esclarecimento quanto às fantasias relacionadas ao procedimento e pós-operatório e acolhimento de ansiedades e angústias relacionadas a todo período pré e pósoperatórios. Em acréscimo, observa-se que a troca de informações e experiências é facilitadora de insights e promove o desenvolvimento de aprendizagens, que engendram um clima de estímulo à atividade em detrimento à passividade.

Fiscmann (1997) corrobora o edifício conceitual de Pichon-Rivière ao afirmar que todo grupo operativo é também terapêutico, um instrumento de trabalho e uma técnica investigativa que cumpre função terapêutica, pois, por não possuir delineamento rígido, é possível o atingimento de múltiplos benefícios a partir dele. Os três momentos que operacionalizam o grupo operativo foram definidos pelo autor como pré-tarefa, tarefa e projeto. Onde por prétarefa compreende-se a expressão da resistência à mudança, o predomínio dos medos básicos e ansiedades frente ao desconhecido que podem impedir a adesão à tarefa. Por tarefa, o segundo momento de um grupo operativo, a resolução de situações estereotipadas e problemáticas que surgem da intensificação das ansiedades diante da situação que se dá na aprendizagem e, finalmente, por projeto, o terceiro momento do grupo operativo, aquilo que aparece emergido da tarefa e o que possibilita o planejamento para o futuro.

\section{POLÊM!CA $\mid$ LABORE}

Polêmica - Revista Eletrônica da Uerj - Rua São Francisco Xavier, $524,1^{\circ}$ andar bloco D, sl.1001 • Tels.: +55 21 2334-4088 / 4087 • http://www.e-publicacoes.uerj.br/index.php/polemica/index http://www.labore.uerj.br • laboreuerj@yahoo.com.br 
Pichon-Rivière, ao analisar a razão da resistência a mudanças e o significado da mudança para cada um, percebe a existência de dois medos básicos em toda a patologia e diante de toda tarefa a iniciar. Para o autor, o medo da perda e o medo do ataque são medos básicos presentes que aparecem em absolutamente todas as situações de mudança. Nesta visada, é interessante acompanhar as narrativas dos pacientes do programa de bariátrica que reiteram o quanto possuem expertise sobre maneiras para atingir a perda de peso e o corpo magro, porém diante de situações de crise, recorrem a conhecidos métodos para refrear a sensação de malestar: a voracidade dirigida à comida. A obesidade talvez represente, assim, a melhor maneira que esses sujeitos conseguiram para estar no mundo.

As resistências podem ser analisadas ainda a partir do abandono da situação previamente conquistada, uma vez que a situação já conhecida, embora desconfortável ou desprazerosa, representa uma segurança para o paciente. Já o medo do ataque, segue situações de mudança recentes, prenunciando novas ansiedades que ocasionarão resistências às mudanças realizadas. Para Pichon-Rivière, o medo de sentir-se pouco ou nada instrumentalizado ou vulnerável para a nova situação antecede o medo do ataque e desnuda a ligação com o medo de perder defesas neuróticas. Desta forma, como proposto por Pichon-Rivière, o medo da perda é o sentimento de perder o que já possuiu, enquanto que o medo do ataque é o sentimento de achar-se indefeso diante de novas situações sem perceber-se dotado do instrumental para lidar com o novo. Segundo o autor, a compreensão desses dois movimentos de resistência orientará a tarefa do grupo, pois há um interjogo constante entre o medo da perda do já conhecido e o medo do ataque do que está por vir.

A aprendizagem implica no abandono, ainda que não completamente consciente, de outras formas de ver, de se estar no mundo. Esse é o dilema que precisa ser atravessado e ultrapassado, ou seja, enfrentar as estereotipias, os comportamentos automáticos e engendrar um algo novo, que por essa qualidade gera ansiedades.

A tarefa no grupo operativo é a resolução das situações de engessamento em qualquer aspecto da vida que se apresente, abrindo espaço para uma postura mais dialética diante da mesma. A técnica possibilita, dessa maneira, a saída de uma situação estancada ou controversa para uma situação de movimento. No entanto, ainda que o objetivo do grupo operativo seja conseguir uma mudança, o grau de modificação atingido dependerá de cada um dos indivíduos que dele fazem parte.

\section{POLÊM!CA $\mid$ LABORE}

Polêmica - Revista Eletrônica da Uerj - Rua São Francisco Xavier, 524, $1^{\circ}$ andar bloco D, sl.1001 • Tels.: +55 21 2334-4088 / 4087 • http://www.e-publicacoes.uerj.br/index.php/polemica/index http://www.labore.uerj.br • laboreuerj@yahoo.com.br 
A partida é o explícito e, tal qual um movimento que Pichon-Rivière reconhece como espiralado, aproximamo-nos do implícito, destacando os aspectos que atuam favorecendo a rigidez, os padrões até chegar a uma nova formulação. Explícito e implícito tomados em termos freudianos e apontando para o tornar consciente o inconsciente. Assim, a tarefa enunciada no grupo é a unidade de trabalho, ou ainda, a explicação do implícito.

Outro importante conceito que tem pertinência nos grupos operativos é o de novo emergente, que diz respeito ao que aparece, a nova perspectiva para a situação que é possibilitada pela interpretação ou assinalação do coordenador do grupo. Em íntima articulação, o porta-voz é o integrante que atua como vetor para que o processo implícito possa se transformar no emergente, funcionando como veículo da qualidade nova. Para Pichon-Rivière (2012), o porta-voz é capaz de sentir uma situação da qual seu grupo está participando e que pode explicitá-la porque está mais próxima de sua mente do que da dos outros membros do grupo.

De forma ilustrativa, a experiência trazida é com os pacientes da equipe de cirurgia bariátrica que possuem como objetivo comum o emagrecimento, sendo, portanto, esta a tarefa explicitada comum a todos os membros do grupo. Para que o emagrecimento possa se dar, são necessárias mudanças de hábitos alimentares, sociais e familiares. Esses são entendidos como a tarefa interna, ou de forma mais clara, as atividades entre as quais cada um dos membros deverá se dedicar para a consecução de seu objetivo. Essas são realizadas por cada um, mas também conjuntamente, uma vez que a todos cabe a mesma tarefa. O encontro semanal favorece que os participantes do grupo possam permanecer próximos e acompanhar uns aos outros em seus processos. Assim, aqueles que perderam peso são festejados ou, também, invejados. Os que não perderam se interrogam e lançam no grupo suas hipóteses. $\mathrm{O}$ grupo acolhe, mas também questiona e instiga para que todos possam manter o compromisso do emagrecimento, mesmo antes que a cirurgia aconteça, como mostraremos adiante.

Os pacientes que já se submeteram ao procedimento bariátrico também comparecem, ora para serem admirados, ora para compartilharem sua experiência com as alegrias e angústia que fazem parte do processo. Via de regra, são recebidos com grande alegria, curiosidade e respondem às perguntas sempre da forma mais franca quanto seja possível para eles. Essa afetiva troca de experiências parece ser aglutinadora e corresponsável pela adesão dos pacientes às orientações da equipe.

\section{POLÊM!CA $\mid$ LABORE}

Polêmica - Revista Eletrônica da Uerj - Rua São Francisco Xavier, $524,1^{\circ}$ andar bloco D, sl.1001 • Tels.: +55 21 2334-4088 / 4087 • http://www.e-publicacoes.uerj.br/index.php/polemica/index http://www.labore.uerj.br • laboreuerj@yahoo.com.br 
Esse breve fragmento do cotidiano grupal auxilia-nos na compreensão dos três momentos do grupo operativo. A entrada na tarefa só é possível quando o grupo pode verbalizar, clarificar e esclarecer o processo de cada um, confrontando-se com seus medos básicos, movimentos de resistência ao novo e medo da perda de referências que os sustentaram até então. A formulação do significado que o emagrecimento tem para um, somada às motivações para atingir esse objetivo, norteia a construção do projeto. A cada semana, a cada novo grupo, o compromisso se renova e é fato corriqueiro entre os pacientes, o destaque dado a esse espaço grupal como lócus de acolhimento e elaboração.

\section{A experiência com grupos no ambulatório de psicologia com pacientes de cirurgia bariátrica}

Partindo da potência vinculadora da instituição hospitalar aos sujeitos que dela se utilizam, quer pela condição de estarem ali a procura de tratamento médico, quer pela relação estabelecida com o próprio hospital e também entre eles, ressaltamos a influência do dispositivo grupal na instituição como tecnologia promotora de mudanças. O grupo se apresenta como uma cena onde a cada um dos sujeitos é permitido expressar-se livremente a partir do seu imaginário, e ao mesmo tempo permite a cada um deles observar os efeitos que suas fantasias produzem no grupo.

A prática doravante explicitada trata de um grupo homogêneo com objetivos de preparo para a cirurgia e também de continente para a experiência de fazer uma intervenção tão radical no corpo que daí poderá surgir a expressão de um mal-estar psíquico, entendemos que dos limitados objetivos de um grupo informativo - que pretende esclarecer dúvidas e fantasias, contribuindo para diminuir ansiedades do paciente e assim auxiliar a entrada na cirurgia, adotando uma postura mais cooperativa e com menor chance de apresentar um distúrbio do comportamento no pós-operatório - transitamos para técnicas mais complexas à medida que os objetivos do grupo tornaram-se mais "ambiciosos". O que equivale a propor uma permanência no grupo mais prolongada, estendendo-se à fase pós-operatória.

Assim, de uma proposta mais informativa e de suporte, caminhamos para um objetivo de conhecimento (insight) e de elaboração ou reflexão. Pensar, refletir como é ser obeso e ter reduzido o estômago, as mudanças no contexto familiar e social produzidas a partir desse lugar e os significados atribuídos à máxima de que para reduzir o estômago é preciso “operar” a

\section{POLÊM!CA $\mid$ LABORE}

Polêmica - Revista Eletrônica da Uerj - Rua São Francisco Xavier, $524,1^{\circ}$ andar bloco D, sl.1001 • Tels.: +55 21 2334-4088 / 4087 • http://www.e-publicacoes.uerj.br/index.php/polemica/index http://www.labore.uerj.br • laboreuerj@yahoo.com.br 
cabeça antes, ou mesmo, a ansiedade e angústia traduzidas pelas assertivas "só operei o estômago e não a mente" ou "continuo com cabeça de gordo".

Um homem jovem em pré-operatório para cirurgia bariátrica traz que a cada refeição sente-se confrontado com um abismo. Sente-se à beira do precipício, em um limite angustiante entre manter-se em constante sensação de alarme, porém 'seguro' ou entregar-se ao cair sem fim, mas prazeroso de sua relação com a comida. O relato antecipa para o grupo uma cena que é comum aos participantes - o flerte com a experiência que se apresenta sedutora e prazerosa, mas que oculta sensações de impotência, fracasso e culpa que resultam em um certo moinho que os massacra e evidencia o sofrimento psíquico de que padecem.

$\mathrm{Na}$ prática clínica, a introdução de um assunto no grupo propicia a investigação dos vários pontos de interseção entre a verticalidade do sujeito que enuncia a questão e horizontalidade do grupo. A enunciação de um problema explicita a possibilidade de elaboração de fantasias que estão bloqueando a atividade grupal. A verticalidade e a horizontalidade do grupo se interpõem, demandando a emergência de um porta-voz que, ao enunciar seu problema, denuncia o conflito da situação grupal em relação à tarefa. Isso deve ser tomado como a horizontalidade ou, melhor compreendido, como o algo em comum compartilhado pela situação grupal.

A explicitação das fantasias que rondam o grupo é parte fundamental para o desenvolvimento do grupo no que tange ao propósito de resolução da tarefa, apresentando-se como mister a clarificação das fantasias universais para permitir que o processo de mudança ocorra.

Em outro exemplo, uma mulher de 48 anos, operada há aproximadamente 3 anos e que já passou pelas cirurgias reparadoras comparece ao grupo e fala das implicações subjetivas de habitar um corpo magro e sentir-se objeto de olhares alheios. Causa curiosidade nos demais aquilo que parecia uma queixa, e que de fato era. $\mathrm{O}$ relato propiciou no grupo o emergir de conteúdos relacionados ao desamparo, desconforto emocional e destinos ocasionados pela falta, mas também pelo excesso do olhar do outro e, nesse sentido, aproximamo-nos da técnica analítica, que é tornar consciente o inconsciente, ou seja, transformar o implícito ou latente em explícito ou manifesto. "De um ponto de vista técnico, parte-se em geral do explícito para descobrir o implícito com o fim de torná-lo explícito e, dessa forma, em um contínuo movimento de espiral" (PICHON- RIVIÈRE, 2012, p. 273).

\section{POLÊM!CA $\mid$ LABORE}

Polêmica - Revista Eletrônica da Uerj - Rua São Francisco Xavier, $524,1^{\circ}$ andar bloco D, sl.1001 • Tels.: +55 21 2334-4088 / 4087 • http://www.e-publicacoes.uerj.br/index.php/polemica/index http://www.labore.uerj.br • laboreuerj@yahoo.com.br 
Espera-se, então, que o grupo, e cada um dos seus membros, possa refletir sobre o conteúdo trabalhado durante a sessão e que possa chegar a uma visão mais ampliada, produzindo um novo conhecimento sobre suas questões e a consequente mudança advinda desse novo saber.

Mais do que interpretar, trata-se de possibilitar ao paciente (e ao grupo) que ele descubra e crie aquela significação com a ajuda do terapeuta, que age como "ambiente facilitador" do desenvolvimento, da terapia, da vida, enfim. O grupo é um excelente espaço para, juntos, descobrirem-se verdades, aspectos de cada um e de todos (MELO FILHO, 2007).

O grupo de pacientes de cirurgia bariátrica realizado no ambulatório pretende-se um grupo de apoio, mas também de análise do ego do paciente, trabalhando as instâncias narcísicas e, ao mesmo tempo, as interpessoais. Isso significa que as repercussões da obesidade, bem como da redução do estômago são abordadas tendo como pano de fundo o universo familiar, social e laborativo do paciente.

O desenvolvimento de um olhar mais integrado do paciente, bem como a garantia de acesso a essa tecnologia, busca cooperar na obtenção de resultados mais positivos no processo de tomada de consciência das necessidades e modificações inerentes ao processo. A garantia da continuidade do apoio psicológico, após a cirurgia, pode ser aqui considerada como um dos fatores da formação do vínculo, detectados através da aderência ao tratamento. Busca-se, com os pacientes, localizar possíveis mantenedores ou causadores de reganho de peso e abordar comportamentos inadequados em relação ao tratamento proposto pela equipe multidisciplinar que possam estar impactando negativamente no resultado obtido.

Neste sentido, acerca da função do olhar do psicólogo, vale ainda lembrar que o mesmo assumirá uma função contingenciadora, devolvendo para o paciente uma imagem mais integrada de si, onde ali havia um corpo despedaçado, cuja libido manteve-se retida em um momento bastante primitivo na vida emocional e psíquica do sujeito. Dessa forma, através da função reparadora e também integrativa do olhar do terapeuta, de uma massa amorfa, um corpo até então em fractais passa a ter um contorno e, assim, a partir do redesenho e da reinvenção de si, a vida vai também, aos poucos, ganhando novos contornos e significações.

Ainda que todos os pacientes sejam acompanhados no período pré-operatório em sessões individuais e também de grupo, urge como amplamente reiterado ao longo do texto, a necessidade da manutenção do mesmo olhar, no período após a realização do procedimento

\section{POLÊM!CA $\mid$ LABORE}

Polêmica - Revista Eletrônica da Uerj - Rua São Francisco Xavier, $524,1^{\circ}$ andar bloco D, sl.1001 • Tels.: +55 21 2334-4088 / 4087 • http://www.e-publicacoes.uerj.br/index.php/polemica/index http://www.labore.uerj.br • laboreuerj@yahoo.com.br 
cirúrgico, pois quadros psiquiátricos como transtornos alimentares e de humor, abuso de substâncias ou outros quadros psiquiátricos não diagnosticados na fase anterior à cirurgia limitam a adesão ao tratamento antiobesidade e mudanças no estilo de vida.

Ademais, não há garantias de que a perda de peso resultará em acréscimo na autoestima, pois a observação clínica nos confronta com o profuso número de pacientes que trilham o percurso da satisfação inicial para as queixas relacionadas à imagem corporal. A grande quantidade de sobra de pele com que precisam conviver por um período considerável, por exemplo, prenuncia situações nas quais persistem sensações de inadequação à ordem estética vigente.

As intensas queixas de desinteresse por parte dos cônjuges e parceiros sexuais ou a vergonha de se desnudar, também é motor para o descontentamento que alimenta o ciclo insatisfação corporal, baixa autoestima, ansiedade, depressão, obesidade. Para esses casos, todos avaliados em retorno no grupo, é solicitado a manutenção de sessões individuais contiguamente. Portanto, o acompanhamento proposto no ambulatório de psicologia ao paciente portador de obesidade grave submetido à cirurgia bariátrica obedece ao disposto pelo Ministério da Saúde, porém não é estanque. Sua flexibilização faz-se presente sempre que necessário, garantindo porta aberta aos acompanhamentos individuais e às sessões de grupo.

Esse modelo de funcionamento estabelecido na equipe garante o suporte e o acompanhamento psicológico aos pacientes, tão logo seja verificado algum aspecto de ordem emocional que possa causar interferência negativa no processo. Manter porta aberta possibilita o acolhimento tão fundamental a pacientes que, frequentemente, apresentam uma psicodinâmica regredida.

Bernadete $^{2}$, uma mulher de 27 anos, agente de saúde, solteira, tem um pós-operatório imediato sem nenhuma intercorrência sob o referencial médico. Com exames clínicos absolutamente dentro dos parâmetros esperados e sem queixas de náuseas ou vômitos. No entanto, em seu retorno ao ambulatório do cirurgião, apresenta-se com intenso sofrimento emocional. A célere perda de peso fomenta uma estranha sensação de não reconhecimento do corpo que agora habita. Uma montanha-russa, como ela expressava, de sentimentos que se alternavam entre bons e ruins. Um corpo que dia a dia se mostra diferente e que perde vertiginosamente seus contornos.

${ }^{2}$ Nome fictício.

\section{POLÊM!CA $\mid$ LABORE}

Polêmica - Revista Eletrônica da Uerj - Rua São Francisco Xavier, 524, $1^{\circ}$ andar bloco D, sl.1001 • Tels.: +55 21 2334-4088 / 4087 • http://www.e-publicacoes.uerj.br/index.php/polemica/index http://www.labore.uerj.br • laboreuerj@yahoo.com.br 
A acentuada reação de Bernadete traduzia questionamentos e medos sobre sua possibilidade de responder ao meio externo, e também ao interno, de forma diferente. Questões que possuem íntima relação com as vivências familiares, sociais e psíquicas de cada um e que necessitarão de um longo trabalho de elaboração e suporte egóico.

O encaminhamento para a psicologia pelo cirurgião foi imediato. Acolhida, Bernardete permaneceu em acompanhamento semanal em grupo, acrescido de sessões individuais que favoreceram que ela pudesse se sustentar e atravessar a crise sem lançar mão de recurso medicamentoso. Tal direção sensível possibilitou a percepção e o reconhecimento paulatino de seus novos contornos, bem como seu fortalecimento para a apresentação das múltiplas intempéries da vida. O grupo, um espelho, um conjunto de experiências, afetos e conhecimentos, que estimula a aceitação à nova imagem corporal e a resposta a críticas do meio, que muitas vezes são projeções de conteúdo internos e apoio a projetos de auto sabotagem.

Desta maneira, incentiva-se a cada começo de atendimento em grupo que um participante dê as boas-vindas aos novos participantes que ali estejam e que explique os objetivos daquele espaço. Esse é um recurso vivo e interessante porque é implementado por aqueles que já passaram pela experiência da cirurgia ou por aqueles que estão em adiantada fase pré-operatória, cabendo a coordenadora adotar uma postura expectante das livres associações que dali surgirão.

Os temas a serem trabalhados podem aparecer naturalmente de um dos membros do grupo e serem estendidos a todos para reflexão, ou serem levantados pelo coordenador. No entanto, são pertinentes ao complexo cirurgia bariátrica e obesidade, sendo que não há rigidez quanto aos conteúdos a serem trabalhados. Ao final de cada encontro, o coordenador transmite ao grupo e a cada participante uma interpretação geral a partir do conteúdo trabalhado naquela sessão "amarrando" as ideias que estiveram presentes no discurso dos participantes.

O compartilhar de vivências corrobora o desenvolvimento de um esquema referencial que seja comum ao grupo e que auxiliará na aprendizagem de um novo contexto, no restabelecimento de redes de comunicação e no fortalecimento egóico por abordar e destruir a resistência a mudanças e auxiliar na reorganização de uma nova etapa, cuja avaliação jaz sob critérios de adaptação ativa à realidade, modificação de si e operação no meio.

\section{POLÊM!CA $\mid$ LABORE}

Polêmica - Revista Eletrônica da Uerj - Rua São Francisco Xavier, $524,1^{\circ}$ andar bloco D, sl.1001 • Tels.: +55 21 2334-4088 / 4087 • http://www.e-publicacoes.uerj.br/index.php/polemica/index http://www.labore.uerj.br • laboreuerj@yahoo.com.br 
Nota-se que, através dos grupos operativos, o sujeito adquire ou recupera um pensamento acerca de si e também do social, obtendo consciência de sua própria identidade e da do outro. Portanto, é dado relevo ao processo terapêutico do qual o grupo é instrumento e que consiste na diminuição dos medos básicos - medo de ataque ao ego (ansiedade paranóide) e medo da perda do objeto (ansiedade depressiva), que são paralisantes a ação do ego, tornandoo impotente. O grupo operativo realizado com os pacientes de cirurgia bariátrica é, assim, um instrumento técnico centrado na tarefa que tem por finalidade aprender a pensar em termos de resolução das dificuldades criadas e manifestadas no campo grupal, e não no campo de cada um dos seus integrantes, o que seria uma psicanálise individual em grupo. No entanto, como proposto por Pichon-Rivière, não é centrado exclusivamente no grupo, mas em cada 'aquiagora-comigo', considerando quem enuncia um acontecimento como porta-voz de si mesmo e das fantasias inconscientes do grupo.

Em resumo, começa-se a interpretar o porta-voz para, ato contínuo, assinalar o explicitado também como um problema grupal. E, enquanto tal, requer a elaboração do e no grupo. Estimula-se que os membros do grupo possam, então, intercambiar ideias, desenvolvendo e estabelecendo estratégias para o manejo da situação-problema inicialmente colocada. O dispositivo grupal na experiência aqui tratada, mostra-se um recurso potente para o manejo e auxílio da minimização dos medos, rompimento de estereótipos fantasmáticos e enfrentamento das novas situações que emergem do próprio processo de ser submetido à uma cirurgia redutora de estômago.

O estímulo à uma posição ativa, assumindo o protagonismo de ações e escolhas, o abandono progressivo das respostas inadequadas a situações ansiogênicas estimulados a todo o momento e o ancoradouro de medos de mudanças são recursos invariavelmente adotados e que promovem os sentimentos básicos de pertença, cooperação e pertinência entre seus membros, que conferem ao grupo produtividade e esteio para os processos de mudança. Observa-se que alguns temas se presentificam de tal modo que fazem parte de um certo complexo de conteúdos que sempre deverão ser referidos ao longo do trabalho de grupo. As profundas alterações corporais e da imagem corporal, as possíveis variações psíquicas que se vislumbram a partir das modificações ocasionadas pela exigência de um novo modus vivendis e também de alimentação, ansiedades e gestão das expectativas e inseguranças frutos de todo esse conjunto de novidades.

\section{POLÊM!CA $\mid$ LABORE}

Polêmica - Revista Eletrônica da Uerj - Rua São Francisco Xavier, 524, $1^{\circ}$ andar bloco D, sl.1001 • Tels.: +55 21 2334-4088 / 4087 • http://www.e-publicacoes.uerj.br/index.php/polemica/index http://www.labore.uerj.br • laboreuerj@yahoo.com.br 
Ainda há outros temas que comparecem com frequência e que poderão ser explorados no trajeto. Entre eles, é possível elencar como pertencentes a esse vasto complexo o estigma da obesidade, as relações interpessoais que são muitas vezes atravessadas por essa condição de obesidade, a sexualidade antes e após o procedimento cirúrgico, o mercado de trabalho e a vida social no pós-cirúrgico.

Ainda acerca da função de um grupo, Corbisier (2011) defende que os grupos vão na contramão do ideário individualista, abrindo uma zona de compartilhamento, de vários espelhos, de várias possibilidades de identificação, tecendo um espaço sempre em transição, sempre em movimento. Vários espelhos que permitem a relativização de muitas categorias, como por exemplo, dos defeitos - o que é defeito para um, pode ser qualidade para o outro ou, como em nossa experiência, troca de estratégias para lidar com a frequente e difícil tarefa de modificar hábitos. Desta maneira, o artifício utilizado por um para atravessar a experiência cirúrgica e necessárias modificações impostas no estilo de vida, podem reverberar para outro.

\footnotetext{
Os grupos são sempre espaços paradoxais, concretos e fluidos, estão sempre no entre - uma situação e outra. Assim, nada mais coerente do que pensá-los como espaços transicionais. Assim como o espaço transicional de Winnicott, que está entre a criança e a mãe, os grupos estão entre cada um e o mundo. Mas, assim como Winnicott diz que a mãe, sinônimo de ambiente, precisa ser suficientemente boa, do meu ponto de vista, o mesmo ocorre com a construção dos grupos. É preciso uma dedicação muito grande, um investimento afetivo suficientemente bom, uma barriga suficientemente boa (...). Nos grupos, podemos falar, gritar, gemer, chorar, cantar, silenciar, até fazer um parto. Porque há um ambiente que protege, que escuta, que cuida, que acolhe, que garante que depois dali poderemos todos ser melhores e diferentes (CORBISIER, 2011, p. 28).
}

Da relação saudável que se estabelece nos grupos e ancorados nos postulados de PichonRivière, mas também na teorização winnicottiana, podemos afirmar que emergem os fundamentos para que o sujeito possa desenvolver instrumentos para lidar com o novo que se constitui. O grupo pode ser percebido dessa forma, como a mãe suficientemente boa, flexível o suficiente para acompanhar o sujeito candidato ou aquele que já realizou a bariátrica em suas necessidades, que oscilam e evoluem no rumo à independência.

\section{Referências}

CAMPOS, E. P. Grupos de Suporte. In: MELlO FILHO, J. (Org.). Grupo e Corpo: psicoterapia de grupo com pacientes somáticos. São Paulo: Casa do Psicólogo, 2007. p. 113-125.

\section{POLÊM!CA $\mid$ LABORE}

Polêmica - Revista Eletrônica da Uerj - Rua São Francisco Xavier, 524, $1^{\circ}$ andar bloco D, sl.1001 • Tels.: +55 21 2334-4088 / 4087 • http://www.e-publicacoes.uerj.br/index.php/polemica/index http://www.labore.uerj.br • laboreuerj@yahoo.com.br 
CORBISIER, C. Grupos e Criatividade: para uma clínica mais humana e solidária. 2011. 133 f. Tese (Doutorado em Psicologia Clínica) - Departamento de Psicologia, PUC-Rio, Rio de Janeiro, 2011.

EHRENBERG, A. The Weariness of the Self: diagnosing the history of depression in the contemporary age. London: McGill-Queen's University Press, 2010.

FISCMANN, J. B. Como Agem os Grupos Operativos? In: ZIMERMAN, D. E. et al. Como trabalhamos com grupos. Porto Alegre: Artemed, 1997. p. 95-100.

FOUCAULT, Michel. A hermenêutica do sujeito. 2. ed. São Paulo: Martins Fontes, 2006.

HAN, Byung-Chul. Sociedade do Cansaço. Petrópolis, RJ: Vozes, 2015.

KHAN, M. M. R. Introdução. In: WINNICOTT, D. W. Da Pediatria à Psicanálise: obras escolhidas. Rio de Janeiro: Imago Ed., 2000. p. 11-54.

LASCH, C. O Mínimo Eu: sobrevivência psíquica em tempos difíceis. São Paulo: Brasiliense, 1986.

MELLO FILHO, J. Atendimento a Pacientes em Grupo. In: BOTEGA, N. J. (Org.). Prática Psiquiátrica no Hospital Geral: interconsulta e emergência. Porto Alegre: ARTMED, 2002. p. 430-444.

Grupos no Hospital Geral: ambulatório, enfermaria e serviços especializados. Grupos homogêneos, heterogêneos e técnica grupal In: ___ (Org.). Grupo e Corpo - psicoterapia de grupo com pacientes somáticos. São Paulo: Casa do Psicólogo, 2007. p. 127-138.

MENDES, N.; VILHENA, J. de. Corpo de Consumo, Corpo Consumido: uma experiência ambulatorial no atendimento a pacientes de cirurgia bariátrica. Polêm!ca, v. 16, n. 3, p. 9-30, ago. 2016. Disponível em: <http://www.e-publicacoes.uerj.br/index.php/polemica/article/view/25244/18041>. Acesso em: 7 jan. 2018. doi:https://doi.org/10.12957/polemica.2016.25244.

MINERBO, M. Psicopatologia Psicanalítica. Notas Críticas. Psicanálise Revista da Sociedade Brasileira de Psicanálise de Porto Alegre, Porto Alegre, v. 11, n. 1, p. 144-164, 2009.

PICHÓN-RIVIÈRE, E. O Processo Grupal. São Paulo: Martins Fontes, 2012.

PINHEIRO, M. T.; QUINTELLA, R. R.; VERTZMAN. J. Distinção teórico-clínica entre depressão, luto e melancolia. Revista Psicologia Clínica, Rio de Janeiro, v. 22, n. 2, p. 147-168, 2010. Disponível em: <http://pepsic.bvsalud.org/scielo.php?script=sci_arttext\&pid=S0103-56652010000200010\&lng=pt\&nrm=iso>. Acesso em: 02 jan. 2019.

RAMAlHO, R.M. A vida por um fio. Revista da Associação Psicanalítica de Porto Alegre - Associação Psicanalítica de Porto Alegre (APPOA), n. 21, p. 17-27, 2001.

SIBILIA, P. O show do eu: a intimidade como espetáculo. Rio de Janeiro: Nova Fronteira, 2008.

SBCBM - SOCIEDADE BRASILEIRA DE CIRURGIA BARIÁTRICA E METABÓLICA. Disponível em: <www.sbcbm.org>. Acesso em: 18 de out. 2017.

WINNICOTT, D. W. (1962). A integração do Ego no Desenvolvimento da Criança. In: O ambiente e os processos de maturação - Estudos sobre a teoria do desenvolvimento emocional. Porto Alegre: Artmed, 1983. p. 55-61.

\section{POLÊM!CA $\mid$ LABORE}

Polêmica - Revista Eletrônica da Uerj - Rua São Francisco Xavier, 524, $1^{\circ}$ andar bloco D, sl.1001 • Tels.: +55 21 2334-4088 / 4087 • http://www.e-publicacoes.uerj.br/index.php/polemica/index http://www.labore.uerj.br • laboreuerj@yahoo.com.br 
(1954). Aspectos Clínicos e Metapsicológicos da Regressão no Contexto Psicanalítico. In: . Da

Pediatria à Psicanálise. Rio de Janeiro: Imago Ed., 2000. p. 374-392.

(1955 [1954]). A Posição Depressiva no Desenvolvimento Emocional Normal. In: Da

Pediatria à Psicanálise. Obras Escolhidas. Rio de Janeiro: Imago Ed., 2000. p. 355-373.

(1956). A Preocupação Materna Primária. In:

Da Pediatria à Psicanálise. Rio de Janeiro: Imago Ed., 2000. p 399-405.

ZIMERMAN, D. E. Fundamentos Básicos das Grupoterapias. Porto Alegre: Artmed, 2007.

Fundamentos Teóricos. In: ZIMERMAN, D.E. et al. Como trabalhamos com grupos. Porto Alegre: Artmed, 1997. p. 23-32.

Atributos Desejáveis para um Coordenador de Grupo. In: ZIMERMAN, D. E. et al. Como trabalhamos com grupos. Porto Alegre: Artmed, 1997. p. 41-48.

Classificação geral dos grupos. In: ZIMERMAN, D. E. et al. Como trabalhamos com grupos. Porto Alegre: Artmed, 1997. p. 75-82.

Recebido em: 01/08/2018.

Aceito em: 30/09/2018.

\section{POLÊM!CA $\mid$ LABORE}

Polêmica - Revista Eletrônica da Uerj - Rua São Francisco Xavier, 524, $1^{\circ}$ andar bloco D, sl.1001 • Tels.: +55 21 2334-4088 / 4087 • http://www.e-publicacoes.uerj.br/index.php/polemica/index http://www.labore.uerj.br • laboreuerj@yahoo.com.br 